\title{
Evaluating quality of life of patients with chronic liver disease: quest for a questionnaire
}

\author{
Uday C. Ghoshal • Ananya Das
}

Received: 3 August 2010 /Accepted: 28 September 2010 /Published online: 10 October 2010

(C) Indian Society of Gastroenterology 2010

Chronic liver disease is associated with significant morbidity and mortality, and is one of the major burdens for health care systems. Several scoring systems are available to evaluate the severity of chronic liver disease [1]; these include the well-known and popular Child-Turcotte-Pugh (CTP) score [2] and the recently established MELD scoring system [3].These scoring systems largely depend on symptoms, signs and laboratory investigations related to the disease. Though many symptoms and signs of chronic liver disease, such as ascites and encephalopathy, may be directly troublesome to patients, laboratory abnormalities such as those in serum albumin and prothrombin time may not be so. Furthermore, several other disabilities that are not included in these scoring systems may trouble the patients more. Patient-reported outcomes are considered more important in assessment of health outcomes. Thus, a holistic system to evaluate the health and well-being from the patient's perspective is of utmost importance [4]. Considering these issues, determining overall quality of life (QOL) is of considerable importance in outcome assessment of chronic diseases [5].

Health-related QOL (HRQL) is often regarded in terms of how QOL is adversely affected by debilitating chronic disease processes. Researchers at the University of Tor-

U. C. Ghoshal

Department of Gastroenterology,

Sanjay Gandhi Postgraduate Institute of Medical Sciences,

Lucknow 226 014, India

\section{A. Das $(\triangle)$}

Arizona Center for Digestive Health,

3420 S. Mercy Road, Suite 211,

Gilbert, AZ 85297, USA

e-mail: adas@azcdh.com onto's Quality of Life Research Unit define QOL as “the degree to which a person enjoys the important possibilities of his or her life." While QOL has long been an explicit or implicit policy goal, an adequate definition and an accurate measurement tool have been elusive [6]. HRQL has been generally described as how well individuals function in daily lives and their own perception of well-being in physical, psychological and social aspects. Instruments used to measure HRQL are broadly of two types: generic and disease-specific [7].

Generic instruments cover the common but important health aspects, and are used to assess and compare HRQL across different health conditions [7]. SF-36 is a popular generic instrument for assessment of HRQL. It consists of eight scaled scores, which are the weighted sums of responses to questions contained in a particular section. Each scale is directly transformed into a $0-100$ scale on the assumption that each question carries equal weight. The eight sections include vitality, physical functioning, bodily pain, general health perception, physical, emotional and social role functioning, and mental health $[7,8]$. In contrast, disease-specific instruments are designed to reflect unique problems most relevant to a particular disease and evaluation of its outcome [7]. Therefore, disease-specific instruments are expected to be more precise and sensitive to pickup changes in HRQL, compared to generic instruments $[7,8]$. Each question for assessment of HRQL, however, has to be adapted to the local population where it is being employed, according to the language, local interpretation of various terminology, lifestyle of the population, and sociocultural and economic issues [9].

Several disease-specific HRQL questionnaires have been developed assessment in specific diseases; [10-13] the chronic liver disease questionnaire (CLDQ) assesses 
QOL in patients with chronic liver disease [14]. In this issue of the Journal, Ray et al, from the eastern part of India, have reported a study on CLDQ assessment of patients with chronic liver disease using a Bengali translation of CLDQ [15]. This translation of CLDQ was found to be reliable.

The authors are to be congratulated in their effort to translate and validate the CLDQ into Bengali, the language spoken by several million people in South Asia, ranking sixth in the list of languages most spoken in the world. Cross-cultural adaptation of an HRQL instrument developed in a different country and in a different language requires attention to two components, viz., a combination of literal translation of individual words and sentences from one language to another and an adaptation with regard to idiom, cultural context and lifestyle. Detailed guidelines have been developed for such cross-cultural adaptation of HRQL measures [9], and it is heartening to note that the authors took care to follow the methodology suggested for development of such a QOL measure.

However, some analytical issues can be raised about the paper. One of the authors' objectives in developing a relevant QOL measure was to understand the impact of socioeconomic factors, etiology, disease severity and complications on QOL of patients with chronic liver disease. Unfortunately, the sample size was small to answer these questions. Only 12 patients had cryptogenic cirrhosis and 7 had cirrhosis due to causes other than alcohol, hepatitis B and C! Of 31 patients with alcoholic cirrhosis, none, 21 and 10 were in Child's A, B and C classes, respectively. Similarly, the numbers of women and elderly patients ( $\geq 55$ years old) were also limited. Conclusions based on such small sample sizes are fraught with risk of statistical errors.

Moreover, possibly because of the limitation imposed by small sample size, the authors performed only univariate analyses; a multivariate regression-based analysis was needed to understand the independent impact of each variable on QOL in patients with chronic liver disease, since many of these variables are likely to be highly correlated. For instance, patients with Child's C disease are more likely to have liver decompensation. Similarly, patients with more severe disease and those with history of decompensation are more likely to face financial burden of expensive investigations, treatment and repeated hospital admissions. Also, the issue of multiple comparisons has not been addressed; thus, some of the significant univariate associations may be invalid.

Another limitation, albeit in broader context, is the practical utility of this work. Busy clinicians in Bengalispeaking areas are unlikely to incorporate a cumbersome QOL measure into their clinical consideration, unless such measures are clearly shown to be helpful in guiding clinical decision making and improving patient care. If the authors of this paper wish that their validated Bengali QOL measure should not languish in the academic domain, they will need to carry out larger studies aimed at demonstrating positive impact of such measures in guiding patient care.

Quality of life measures are crucial instruments in moving modern medicine from the realm of providerdriven interventions to patient-centric participatory medicine in which patients shift from being mere passengers to responsible drivers of their health. In this context, the effort by Ray et al is surely a welcome small but important step in the right direction.

"A journey of a thousand miles begins with a small step" - Lao Tzu, Chinese Founder of Taoism (570$490 \mathrm{BC})$

\section{References}

1. Ghoshal UC, Das A. Models for prediction of mortality from cirrhosis with special reference to artificial neural network: a critical review. Hepatol Int. 2008;2:31-8.

2. Child III CG, Turcotte JG. Surgery and portal hypertension. In: Child III CG, editor. The liver and portal hypertension. Philadelphia: Saunders; 1964. p. 50-8.

3. Kamath PS, Kim WR. The model for end-stage liver disease (MELD). Hepatology. 2007;45:797-805.

4. Fitzpatrick R, Davey C, Buxton MJ, Jones DR. Evaluating patient based outcome measures for use in clinical trials. Health Technol Assess. 1998;2:i-iv. 1-74.

5. Costanza R, Fisher B, Ali A, et al. An integrative approach to quality of life measurement, research, and policy, S.A.P.I.EN.S, 1.1 2008, [Online], Online since 19 décembre 2008. URL: http:// sapiens.revues.org/index 169.html. Connection on 03 août 2010.

6. Quality of Life: How Good is Life for You?. University of Toronto Quality of Life Research Unit. http://www.utoronto.ca/ qol/. http://www.qualityoflifecare.com/?page id=50.

7. Guyatt GH, Feeny DH, Patrich DL. Measuring health-related quality of life. Ann Intern Med. 1993;118:622-9.

8. Patrick DL, Deyo RA. Generic and disease-specific measures in assessing health status and quality of life. Med Care. 1989;27 Suppl 3:217-32.

9. Guillemin F, Bombardier C, Beaton D. Cross-cultural adaptation of health-related quality of life measures: literature review and proposed guidelines. J Clin Epidemiol. 1993;46:1417-32.

10. Cronin L, Guyatt G, Griffith L, et al. Development of a healthrelated quality-of-life questionnaire (PCOSQ) for women with polycystic ovary syndrome (PCOS). J Clin Endocrinol Metab. 1998;83:1976-87.

11. Saadat S, Javadi M, Divshali BS, et al. Health-related quality of life among individuals with long-standing spinal cord injury: a comparative study of veterans and non-veterans. BMC Public Health. 2010;10:6.

12. Saharinen T, Hintikka J, Niskanen L, et al. Health-related quality of life among subjects with long-term mental symptoms in a population-based sample. J Psychiatr Ment Health Nurs. 2010;17:260-7. 
13. Filocamo G, Schiappapietra B, Bertamino M, et al. A new short and simple health-related quality of life measurement for paediatric rheumatic diseases: initial validation in juvenile idiopathic arthritis. Rheumatology (Oxford). 2010;49:1272-80.

14. Younossi ZM, Guyatt G, Kiwi M, Boparai N, King D. Development of a disease specific questionnaire to measure health related quality of life in patients with chronic liver disease. Gut. 1999;45:295-300.

15. Ray I, Dutta D, Basu P, De BK. Quality of life assessment of patients with chronic liver disease in eastern India using a Bengali translation Chronic Liver Disease Questionnaire. Indian J Gastroenterol. 2010;29. doi:10.1007/s12664-010-0036-x. 